\section{Diagrama de Flujo para la Evaluación de Pro- gramas de Formación de Postgrado}

\section{Flow sheet to evaluate Post Graduate Teaching Programs}

\section{Sr. Editor:}

La acreditación de los programas de formación de postgrado en Chile fue definida en la Ley 20.129, vigente desde $2006^{1}$. Acredita los programas la Comisión Nacional de Acreditación (CNA), constituida de acuerdo a la misma ley. Dicha comisión emite un veredicto basándose en el informe evacuado por agencias acreditadoras independientes, autónomas, que permiten realizar un proceso justo, estandarizado y libre de presiones. La primera (y única por el momento) agencia evaluadora es
APICE (Agencia de Acreditación de Programas y Centros de Formación; www.apicechile.cl), desde el año 2009. Esta agencia nombra una comisión de pares evaluadores, quienes verifican que se cumplan los requisitos mínimos exigidos a los programas de post título para ser acreditados. Es una actividad voluntaria, muy deseable por los programas de formación de postgrado ya que confiere autonomía a sus egresados, sin que su certificación de especialidad deba ser visada por la Corporación Nacional Autónoma de Certificación de Especialidades Médicas (CONACEM).

Para iniciar el proceso, el centro formador postulante debe redactar un documento-postulación donde describa en detalle su programa, siguiendo una pauta en que aparecen los requisitos generales y específicos para cada programa. Aunque estos

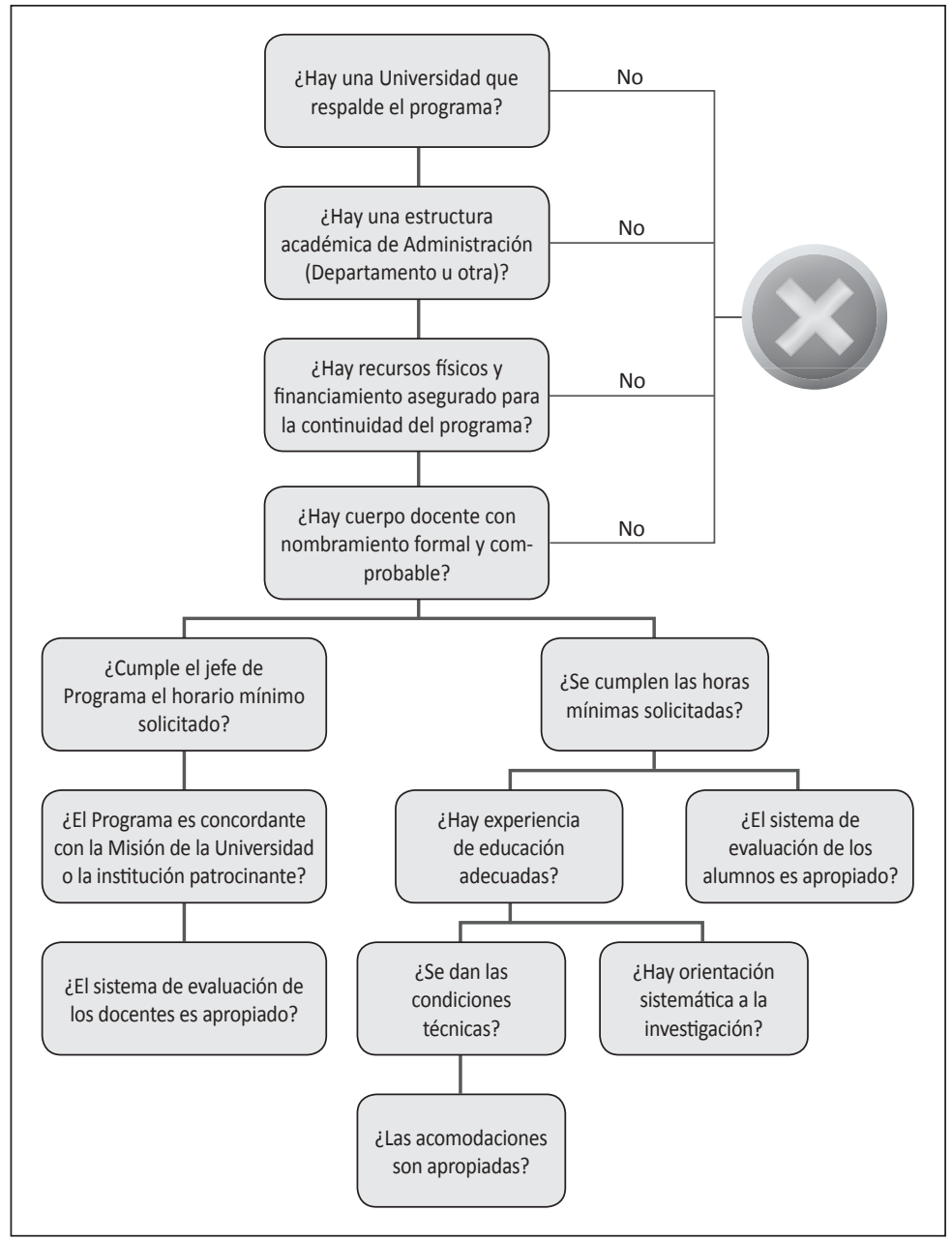

Figura. Diagrama de flujo para interpretar los estándares de acreditación de los programas de formación de postgrado.

- Las primeras 4 cajas son de carácter obligatorio. Si falta una, no se puede seguir avanzando.

- Las siguientes cajas, son muy deseables que estén. Cada comisión debe definir los estándares umbrales, de acuerdo a las directrices de APICE o la que corresponda en su momento.

- Las cajas inferiores se llenan al integrar la evaluación de todos los aspectos relevantes de cada tema (ej. ¿Las acomodaciones son apropiadas?: deben existir acomodaciones adecuadas en todos los campus donde se desarrolle la docencia, que incluyan salas de estar, casilleros, computadores con conexión a Internet, etc). 
estándares están explícitos en los documentos facilitados a los postulantes y evaluadores, no se hace evidente un orden ni categorización por importancia de los requisitos, que permitan valorar sus aspectos obligatorios, sin los cuales el proceso no puede seguir adelante.

Actualmente, hay 12 Facultades de Medicina que ofrecen 228 programas de formación de especialistas $^{2}$. A su vez, hay 53 diferentes especialidades a ser acreditadas, por un contingente de más de 270 pares evaluadores ${ }^{3}$, por lo que el público potencialmente interesado en entender, dominar y agilizar el proceso, es alto. Consecuentemente elaboramos un diagrama de flujo (Figura), desarrollado después de participar en dos procesos de acreditación y que esquematizan el proceso de verificación de los estándares por la comisión acreditadora. Creemos que puede facilitar el proceso de preparación de los antecedentes, por la Universidad que postula a la acreditación. Evidentemente se deben precisar o acotar algunos puntos en el diagrama como, por ejemplo, las horas docentes mínimas y su concordancia con el rol de la Universidad. La presentación de los requisitos como un diagrama de flujo, con categorización por importancia del ítem, podría facilitar y hacer más eficiente el proceso de acreditación. Aún cuando el informe de evaluación puede ser utilizado como un método diagnóstico, a partir del cual se trabaje para implementar lo requerido para la acreditación, la documentación exigida para presentarse al proceso requiere de una autoevaluación previa del programa. En esta, los puntos indispensables deberían estar identificados y analizados. Un esquema como el que presentamos puede ayudar en esta etapa, tanto a facilitar su implementación para cumplir lo solicitado, como para verificar el correcto cumplimiento de lo exigido.

Hector J. Lacassie ${ }^{1}$, Mario Concha P. ${ }^{1}$, Ana María Espinoza $U^{2}$ ${ }^{1}$ División de Anestesiología, Facultad de Medicina, Pontificia Universidad Católica de Chile ${ }^{2}$ Departamento de Anestesiología, Facultad de Medicina, Universidad de Chile. Santiago de Chile.

\section{Referencias}

1. Ministerio De Educación. Establece un Sistema Nacional de aseguramiento de la Calidad de la educación Superior. Biblioteca del Congreso Nacional de Chile. Disponible en: http://tinyurl.com/3mckvy9 [Consultado el 4 de abril de 2011]

2. Apice. Noticias. Disponible en: http://tinyurl.com/ 3h7z83a [Consultado el 4 de abril de 2011]

3. Apice. Evaluadores. Disponible en: http://tinyurl.com/ 4yteyf2 [Consultado el 4 de abril de 2011] 